\title{
Outcomes of over-the-scope clip application in various gastrointestinal indications: experience from a tertiary care in India
}

\author{
Radhika Chavan, Zaheer Nabi, Arun Karayampudi, Nitin Jagtap, Shujaath Asif, \\ Raghvendra Yaralagadda, Jahangeer Basha, Sundeep Lakhtakia, Manu Tandan, Mohan Ramchandani, \\ D Nageshwar Reddy
}

Asian Institute of Gastroenterology, Hyderabad, India

\section{Abstract}

\begin{abstract}
Background Recent advances in endoscopic tools and techniques have allowed the minimally invasive management of iatrogenic gastrointestinal (GI) perforations and bleedings. However, surgery may be required in cases with larger defects and bleeding refractory to conventional endoscopic modalities. The use of over-the-scope clips (OTSC) has been shown to improve the outcomes in these patients compared with conventional treatment modalities. In this study, we evaluated the safety and efficacy of OTSC for different indications in the GI tract.
\end{abstract}

Methods The data of consecutive patients in whom OTSC was utilized for different indications between February 2017 and October 2019 were analyzed retrospectively. The following outcomes were recorded: technical and clinical success, and adverse events related to the procedure.

Results Thirty-six patients (22 male, mean age $52.673 \pm 14.97$ years, range 11-72 years) underwent OTSC application. Indications for OTSC were: GI defects (perforation $n=13$, fistula $\mathrm{n}=5$ ); esophageal metallic stent fixing $\mathrm{n}=9$; GI bleeding $\mathrm{n}=8$; and neuroendocrine tumor endotherapy $\mathrm{n}=1$. The average size of the defect was $15.88 \pm 8.01 \mathrm{~mm}$. The technical and clinical success rates were $88.89 \%$ and $83.33 \%$, respectively. There were $4(11.1 \%)$ technical failures: colonic perforations $\mathrm{n}=2$; duodenal ulcer bleeding $\mathrm{n}=1$; and esophageal metal stent fixation $\mathrm{n}=1$. There were $2(9.5 \%)$ adverse events, including 1 partial duodenal obstruction and 1 delayed bleeding.

Conclusions The use of OTSC is safe, easy and effective for various indications in the GI tract. Prospective trials are required to see if the use of OTSC is cost effective as a primary endoscopic treatment method in these cases.

Keywords Endoscopy, bleeding, perforation, full-thickness resection

Ann Gastroenterol 2020; 33 (5): 1-7

\section{Introduction}

Over the last several decades, the utilization of endoscopy for both diagnostic and therapeutic purposes has increased substantially. With more frequent utilization of endoscopy,

Department of Gastroenterology, Asian Institute of Gastroenterology, Hyderabad, India

Conflict of Interest: None

Correspondence to: Zaheer Nabi, Asian institute of Gastroenterology, 6-3-661, Somajiguda, Hyderabad-500082, India,

e-mail: zaheernabi1978@gmail.com

Received 8 April 2020; accepted 15 May 2020; published online 30 June 2020

DOI: https://doi.org/10.20524/aog.2020.0515 especially for therapeutic indications, the incidence of complications such as bleeding and perforation has also increased [1]. Traditionally, these complications have been managed with surgery. Developments in endoscopic hemostatic techniques and closure devices have reduced the need for surgery in majority of the cases [2]. However, surgery may be required in large gastrointestinal (GI) defects and upper GI bleeding refractory to conventional hemostatic modalities. Novel innovations in endoscopic closure devices have allowed the endoscopist to close larger perforations and manage refractory GI bleedings. One such innovation is over-the-scope clips (OTSC), recently introduced for the management of GI defects and acute GI bleeding episodes [3-9]. Although multiple studies from western countries attest to their safety and efficacy, there are limited data from India describing their utility in this regard [6]. In this series, we aimed to evaluate the safety and efficacy of OTSC for various indications in the GI tract. 


\section{Patients and methods}

The data of all the patients in whom OTSC was used for different indications from February 2017 to October 2019 were analyzed retrospectively. The exclusion criteria were age $<5$ years, limited jaw opening, hemodynamic instability, iatrogenic perforations with signs of peritonitis and sepsis, and luminal narrowing at the site of OTSC application. Informed consent was obtained from all patients, or legal guardians in the case of minors. The study was approved by the institutional review board.

\section{Outcomes}

The following details were recorded pertaining to the procedure: indication of the procedure; size and location of GI defect; size and type of OTSC used; use of OTSC anchor or twin grasper; and details of prior endoscopic therapies. The primary outcome of the study was clinical success, as defined by the resolution of the underlying problem: i.e., control of GI bleeding, and closure of perforation or GI wall defect as visible on endoscopy or contrast study. In cases where OTSC was used to prevent stent migration, an absence of stent migration for the intended duration was considered as clinical success. Secondary outcomes included the need for reintervention and adverse events related to the application of OTSC.

\section{Device and technique}

The OTSC system set (Ovesco Endoscopy, Tübingen, Germany) includes an applicator cap with a mounted OTSC clip, thread, thread retriever and a hand wheel for clip release. The OTSC clip is made of nitinol and is available in 3 different sizes: $11 \mathrm{~mm}, 12 \mathrm{~mm}$, and $14 \mathrm{~mm}$. The clip has 3 different claw shapes designed for different indications (Fig. 1). The OTSC device is preloaded on a transparent cap compatible with scopes of various diameters $(8.5-11.5 \mathrm{~mm})$. For stent fixation, a specially modified cap was used for anchoring the stent (Stentfix OTSC, Ovesco Endoscopy, Tübingen, Germany).

The OTSC was mounted over the tip of the gastroscope and released by tightening the thread with the hand wheel. The use of a twin grasper or anchoring device to assist the closure of defects was left to the discretion of the endoscopist performing the procedure [10]. Three endoscopists with formal training in OTSC performed all the procedures.

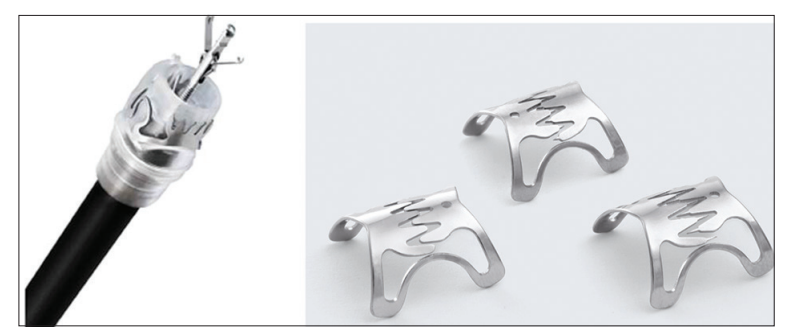

Figure 1 Over-the-scope clip device system with 3 different types of clips

\section{Follow up}

In cases with GI bleeding, a follow-up endoscopy was performed within 24-48 h if clinically indicated, or in cases where the application of OTSC was felt to be suboptimal on index endoscopy. All the patients with ulcer-related bleeding were managed with a standardized protocol of intravenous infusion of proton pump inhibitors $(80 \mathrm{mg}$ bolus followed by $8 \mathrm{mg} / \mathrm{h}$ of pantoprazole or esomeprazole). Endoscopy was performed at 8 weeks to confirm ulcer healing.

In cases with GI wall defects, an oral contrast study was performed on the day following the procedure. Oral liquids were allowed if no leak was found on oral contrast study. Subsequently, endoscopic evaluation was performed at 4-8 weeks.

In cases where OTSC were used for fixation of esophageal metal stents, a chest $\mathrm{x}$-ray or fluoroscopic examination was performed prior to the patient's discharge, i.e., within 48$72 \mathrm{~h}$. Subsequently, the patients were followed at 4-8 weeks and endoscopy and or chest $\mathrm{x}$-ray was performed to look for stent migration. Endoscopy or radiological examination on subsequent follow-up visits was performed if clinically indicated.

\section{Definitions}

Technical success: successful application of the clips at the desired location.

Clinical success: achievement of the desired outcome without subsequent need for reintervention.

\section{Statistical analysis}

The data are presented as mean \pm standard deviation. Student's paired $t$-test was used for continuous variables and the proportion test for categorical variables. A P-value $<0.05$ was considered statistically significant.

\section{Results}

Thirty six patients (22 male, mean age $52.63 \pm 14.97$ years, range 11-72 years) underwent OTSC application. The most common indications for OTSC application were: GI defects $n=18$; fixation of esophageal self-expandable metallic stent (SEMS) $\mathrm{n}=9$; bleeding $\mathrm{n}=8$; and endotherapy for neuroendocrine tumor $n=1$ (Table 1). The mean size of GI defects was $15.88 \pm 8.01 \mathrm{~mm}$.

\section{Overall outcomes}

In this series, 2 different types of OTSC systems were used for different indications. A standard OTSC system was used 
for hemostasis and closure of GI defects $(n=26)$ and an OTSC stent fixation system for fixation of esophageal metal stents $(n=7)$. Traction devices were used in $11(57.89 \%)$ cases with GI defects. For small and acute perforations $(n=7)$, moderate suction was used before clipping. Technical and clinical success

Table 1 Characteristics of patients who underwent over-the-scope clipping for various GI disorders

\begin{tabular}{|c|c|}
\hline Characteristics & Value \\
\hline Total no. of patients & 36 \\
\hline Age (mean \pm standard deviation) & $52.63 \pm 14.97(11-72)$ \\
\hline Sex (Male: Female) & 22:14 \\
\hline $\begin{array}{l}\text { Indication } \\
\text { GI defects } \\
\text { Iatrogenic perforation } \\
\text { Diagnostic procedure-related } \\
\text { Therapeutic procedure } \\
\text { EUS-related } \\
\text { Post-ESD for duodenal tumor } \\
\text { Fistulas } \\
\text { Tracheoesophageal fistula } \\
\text { Duodenal fistula in Crohn's disease } \\
\text { Esophageo-mediastinal fistula } \\
\text { Post Roux-en-Y gastric bypass leak }\end{array}$ & $\begin{array}{c}18 \\
13 \\
7 \text { (Colonoscopy: } 4 \text {, EUS: } 3 \text { ) } \\
6 \\
4 \text { (EUS GJ: } 3 \text {, EUS CDS: } 1 \text { ) } \\
2 \\
5 \\
2 \\
1 \\
1 \\
1\end{array}$ \\
\hline Metallic stent fixing & 9 (Benign: 3, malignant: 6) \\
\hline GI bleeding & 8 \\
\hline Neuroendocrine tumor endotherapy & 1 \\
\hline Size of the defect & $15.88 \pm 8.01$ \\
\hline Size of OTSC & $\begin{array}{l}11 \mathrm{~mm}: \\
12 \mathrm{~mm}: \\
14 \mathrm{~mm}: \\
\text { Stent fix: }\end{array}$ \\
\hline $\begin{array}{l}\text { Retraction device (anchor or twin } \\
\text { grasper) used for GI defect closure }\end{array}$ & $57.89 \%$ \\
\hline Adverse events & $\begin{array}{c}2 \\
\text { Delayed bleeding: } 1 \\
\text { Partial duodenal } \\
\text { obstruction: } 1\end{array}$ \\
\hline Technical success & $88.9 \%$ \\
\hline Clinical success & $83.3 \%$ \\
\hline
\end{tabular}

ESD, endoscopic submucosal dissection; EUS, endoscopic ultrasound; EUS GJ, endoscopic ultrasound guided gastrojejunostomy; EUS CDS, endoscopic ultrasound-guided choledochoduodenostomy; GI, gastrointestinal; OTSC, over-the-scope clip were recorded in $88.9 \%$ and $83.33 \%$ of cases, respectively. Clinical outcomes were better in cases with indications other than GI defects as compared to those with GI defects $(88.89 \%$ vs. $77.78 \%, \mathrm{P}=0.6581$ ).

\section{Outcomes according to indications}

\section{Closure of GI defects}

OTSC was used for the closure of GI defects in 18 cases, including iatrogenic perforations $(n=13)$ and fistula $(n=5)$ (Fig. 2). The location and etiologies of GI defects are shown in Table 1. The mean sizes of iatrogenic perforations and fistulas were $17.38 \pm 8.65$ and $12.00 \pm 4.69(\mathrm{P}=0.212)$, respectively. All sizes of clips ( $11 \mathrm{~mm}$ in $8,12 \mathrm{~mm}$ in 8 and $14 \mathrm{~mm}$ in 2), with 2 different shapes ("a" type in 5 and " $\mathrm{t}$ " type in 13), were used to close GI defects. Overall, technical success and clinical success were achieved in 16 (88.89\%) and 14 (77.78\%) patients, respectively. There were 2 technical failures in the perforation group vs. none in the fistula group. Both the perforations where OTSC could not be applied successfully were located near the sigmoid bend and were larger than $2 \mathrm{~cm}$ in size. There were 2 recurrences in the fistula group on follow up. Clinical success was higher in cases with iatrogenic perforations as compared to fistula closure $(84.6 \%$ vs. $60 \%, \mathrm{P}=0.532)$. However, the difference was not statistically significant.

\section{Stent anchoring}

A specially designed OTSC system was used in 7 of the 9 cases where esophageal SEMS were placed for benign $(n=3)$ or malignant $(n=6)$ indications (Fig. 3). Fully covered SEMS $(n=3)$ were placed for benign lesions, while uncovered $(n=4)$ and partially covered $(n=2)$ SEMS were placed in malignant pathology. In 3 cases, the OTSC was placed after encountering stent migration on the following days. In 6 cases OTSC was used immediately following the stent deployment. Technical success was achieved in $8(88.89 \%)$ patients. In 1 patient OTSC could not be deployed because of a technical fault in the device system. There was no incidence of stent migration at first follow up (4 weeks). In 3 cases where esophageal SEMS were placed for a benign indication, the clip was successfully removed after 4-8 weeks using a Direct Current cutter device.
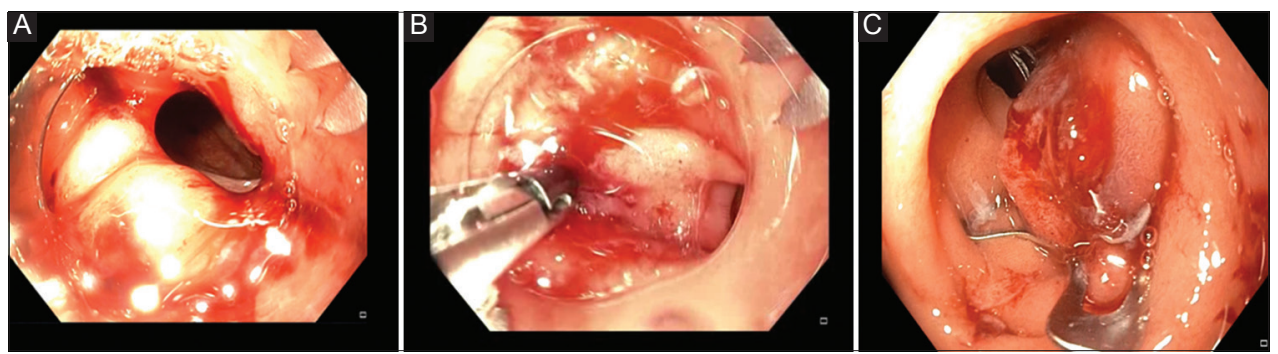

Figure 2 (A) Duodenal perforation during diagnostic endoscopic ultrasound. (B) Approximating edges of duodenal perforation using twin grasper. (C) Closure of duodenal perforation with over-the-scope clip 


\section{Gl bleeding}

OTSC was used in 8 patients with non-variceal upper GI bleeding as primary therapy $(n=5)$ and rescue therapy $(n=3)$. The etiologies and characteristics of patients with upper GI

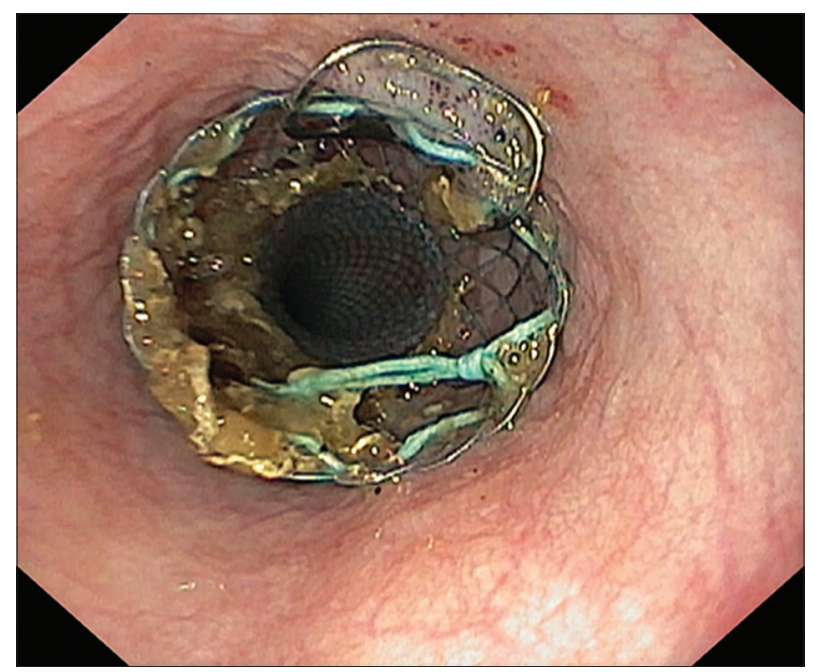

Figure 3 Fixing of esophageal self-expandable metallic stent with novel over-the-scope clip stent fixation system bleeding are outlined in Table 2. Two size of clips (11 $\mathrm{mm}$ in 6 and $12 \mathrm{~mm}$ in 2 cases), with 2 different shapes ("a" type in 7 cases and " $t$ " type in 1 with diverticular bleed), were used to control bleeding.

Technical and clinical success of OTSC were achieved in $87.5 \%$ and $100 \%$ cases, respectively. There were no incidences of in-hospital rebleeding in either primary or rescue groups. There was 1 technical failure in this group. In this case with duodenal ulcer bleeding, the scope with the OTSC mounted could not be maneuvered into duodenum because of pyloric channel narrowing. There were no major adverse events related to OTSC application. In 1 case, asymptomatic duodenal narrowing was noticed after OTSC application (Fig. 4).

\section{Subepithelial resection}

OTSC was used for the management of a neuroendocrine tumor in the duodenal bulb (15 $\mathrm{mm})$. The case was presumed to be at high risk of bleeding due to underlying portal hypertension, coagulopathy (international normalized ratio 2.5) and thrombocytopenia (platelet count 40,000/ $/ \mathrm{L}$ ). Band ligation and endoloop of the tumor was attempted but was not successful. This could be because the relatively larger size of the tumor and the sessile nature of the lesion made it

Table 2 Characteristics of patients with gastrointestinal bleeding who underwent OTSC placement

\begin{tabular}{|c|c|c|c|c|c|c|c|c|c|c|c|}
\hline No. & Age & sex & $\begin{array}{l}\text { GBS } \\
\text { score }\end{array}$ & $\begin{array}{l}\text { Anti } \\
\text { coagulation }\end{array}$ & $\begin{array}{l}\text { Endoscopic } \\
\text { finding }\end{array}$ & $\begin{array}{c}\text { Size of } \\
\text { lesion }(\mathrm{mm})\end{array}$ & $\begin{array}{l}\text { Previous } \\
\text { therapy }\end{array}$ & $\begin{array}{c}\text { Size }(\mathrm{mm}) \\
\text { shape of OTSC }\end{array}$ & Success & $\begin{array}{l}\text { Additional } \\
\text { measures }\end{array}$ & Complication \\
\hline 1 & 70 & $\mathrm{M}$ & 13 & yes & $\begin{array}{l}\text { Cameron } \\
\text { ulcer with } \\
\text { oozing }\end{array}$ & 10 & No & $11, \mathrm{a}$ & Yes & No & No \\
\hline 2 & 65 & M & 11 & No & $\begin{array}{l}\text { Fibrotic DU } \\
\text { (FIIA) }\end{array}$ & 8 & $\begin{array}{l}\text { Epinephrine } \\
\text { injection+ } \\
\text { Gold probe } \\
\text { therapy }\end{array}$ & $11, \mathrm{a}$ & Yes & No & No \\
\hline 3 & 63 & $\mathrm{~F}$ & 12 & Yes & $\begin{array}{l}\text { D3 } \\
\text { diverticula } \\
\text { on medial } \\
\text { wall with } \\
\text { spurting }\end{array}$ & 12 & No & $12, \mathrm{t}$ & Yes & No & No \\
\hline 4 & 61 & M & 14 & No & DU (F I B) & 10 & $\begin{array}{l}\text { Epinephrine } \\
\text { injection+ } \\
\text { Gold probe } \\
\text { therapy }\end{array}$ & $11, \mathrm{a}$ & Yes & No & No \\
\hline 5 & 43 & M & 9 & No & DU (F II B) & 11 & No & 12 , a & Yes & No & $\begin{array}{l}\text { Partial luminal } \\
\text { narrowing } \\
\text { at D1-D2 } \\
\text { junction }\end{array}$ \\
\hline 6 & 60 & $\mathrm{~F}$ & 11 & No & DU (F IIA) & 10 & No & $11, \mathrm{a}$ & $\begin{array}{l}\text { No } \\
\text { Failed to } \\
\text { cross pylorus }\end{array}$ & $\begin{array}{l}\text { Angi } \\
\text { oembolization }\end{array}$ & No \\
\hline 7 & 45 & M & 10 & No & DU (F IA) & 8 & $\begin{array}{l}\text { TTS } \\
\text { clipping }\end{array}$ & $11, \mathrm{a}$ & Yes & No & No \\
\hline 8 & 34 & M & 12 & No & DU (F IIA) & 10 & No & $11, \mathrm{a}$ & Yes & No & No \\
\hline
\end{tabular}


difficult to capture the whole lesion for band ligation and endoloop, respectively. OTSC was used as a rescue therapy and was applied to the tumor's base. After application of OTSC, an endoloop was applied below the OTSC to ensure complete strangulation of the tumor (Fig. 5). The patient presented with GI bleeding within 5 days of the procedure. However, there was no active bleeding on endoscopy and the patient improved with conservative management. Follow-up endoscopy at 6 months of follow up showed no endoscopically visible recurrence.

\section{Discussion}

In this series, we found that OTSC is safe and easy to use for GI defects and bleedings. In addition, the newly available OTSC was effective in securing esophageal metal stents for the intended duration. GI bleeding and perforations are the 2 most common feared complications encountered by a endoscopist. Small perforations and a majority of the luminal bleedings can be efficiently managed using through-the-scope clips. However, surgery may be required in cases with larger defects and refractory GI bleedings. In addition, through-the-scope clips are not effective in certain circumstances, such as fistula closure and fixation of metal stents (especially esophageal).

In this case series, we evaluated the use of OTSC for various indications, including acute non-variceal upper GI bleeding, GI defects, fixation of esophageal covered metal stents and management of a duodenal neuroendocrine tumor. The technical success of OTSC application was high in this study, which indicates the ease of application of these clips.

GI defects, including iatrogenic perforations and tracheoesophageal fistulas, were the most common indications for
OTSC in the present series. Clinical success rates were lower in this group compared to other indications $(77.78 \%$ vs. $88.89 \%)$. Similarly, the success rate of fistula and leak closure was lower than that of acute iatrogenic perforations (60\% vs. $84.61 \%$ ). However, the difference was not significant, probably because of the small sample size. Our results are consistent with those of a large multicenter study, where the closure of perforations and leaks was significantly more successful than the closure of fistulas ( $90 \%$ vs. $42.9 \%$ ) [3]. The lower success rates for fistula closure could be due to difficulty in grasping the fibrotic or retracted edges of chronic fistulas [11]. Another disadvantage of the OTSC clip is that the large size of the cap makes it difficult to negotiate sharp bends and a narrow GI lumen [12]. In the present series, OTSC could not be applied successfully in 2 cases with colonic perforations. In both cases, the perforations were large $(>2 \mathrm{~cm})$ with irregular margins and were located at or near the sigmoid bend.

The OTSC system comes with traction equipment, including a twin grasper and a tissue anchor. Alternatively, suction can be used effectively in cases with perforations or GI defects. In this series, we used suction and traction techniques in 7 and 11 patients, respectively. The use of the twin grasper has been shown to increase clinical success, especially when it is used for leaks and fistulas [13]. In our experience, suction provided adequate results in cases with small and acute perforations, whereas the use of traction was felt necessary in cases with fistulas and large perforations.

OTSC was used to secure esophageal SEMS in 9 cases, with a high technical success rate (89\%). There was no case of stent migration at 4 -week follow up. In concordance with our results, Watanabe et al reported excellent outcomes while using OTSC clips to prevent stent migration in 12 patients with malignant esophageal strictures [14]. However, the authors used
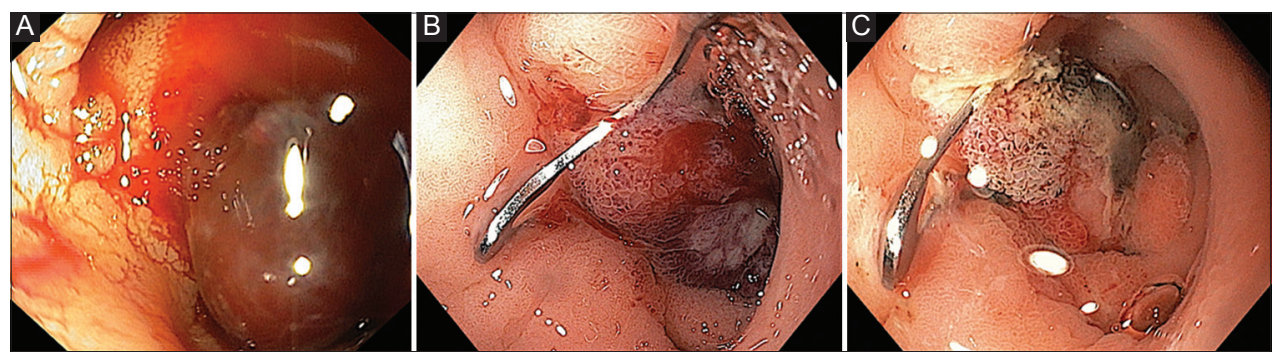

Figure 4 (A) Duodenal ulcer with large adherent clot. (B) Over-the-scope clip (OTSC) applied after dislodging the adherent clot. (C) Repeat endoscopy revealed partial duodenal obstruction due to OTSC

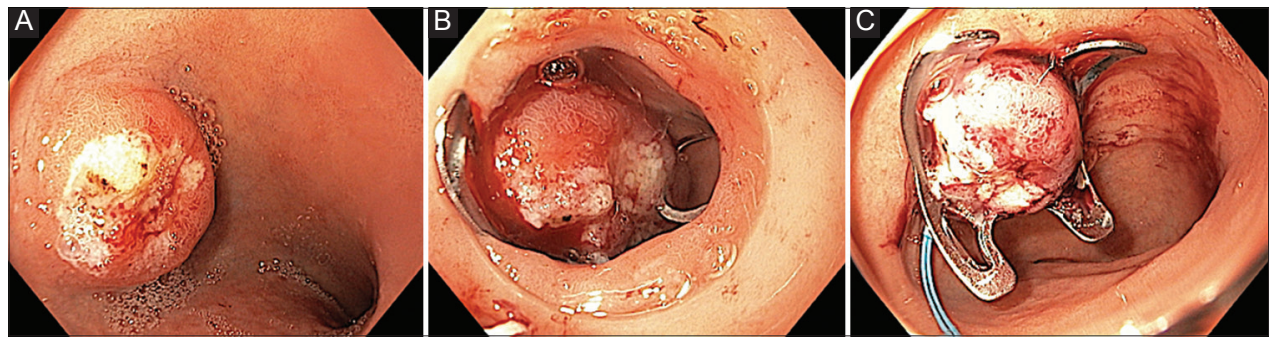

Figure 5 (A) Duodenal neuroendocrine tumor (NET) with surface ulceration. (B) Over-the-scope clip (OTSC) applied to the base of duodenal NET. (C) Endoloop applied below the OTSC to duodenal NET 
conventional type OTSC clips in this study. The advantages of using the novel OTSC (StentFix) over conventional OTSC are the rounded clip design, which adapts to the GI lumen without causing any luminal obstruction, and the modified cap, which enables parallel alignment of the clip in relation to stent opening and helps capture adequate stent mesh and tissue. Although the use of through-the-scope clips and endoscopic suturing methods have been described for stent fixation, the downsides are the relative inefficacy of through-the-scope clips and a steep learning curve for endoscopic suturing. In addition, the tangential working angle may make it difficult to obtain adequate suture depth in the esophagus.

The reported rates of stent migration after OTSC (16.7\%) are comparable with those after endoscopic suturing $(17 \%)[8,15]$. To our knowledge, this is the first series to describe the outcomes of a novel OTSC system designed especially for fixation of esophageal metal stents.

Another common indication for OTSC is GI bleeding. Successful outcomes were achieved in all but 1 case with duodenal ulcer bleeding, where the clip could not be applied because of pyloric narrowing. There were no cases of rebleeding after successful application of OTSC. Notably, OTSC was used as a primary therapy in most cases (62.5\%). In these cases, all the ulcers were high-risk types-(Forrest I and II) with high Glasgow Blatchford scores on admission-and the use of through-the-scope clips or thermal hemostatic modalities was judged to be difficult or risky given the large ulcers with a fibrotic base. OTSC has been shown to be more effective than through the scope clips in recurrent peptic ulcer bleeding cases [16]. In a meta-analysis of 21 studies $(n=851)$, technical and clinical success were reported in $97.8 \%$ and $96.6 \%$ patients, respectively. Rebleeding was seen in $10.3 \%$ of patients. The failure rate of OTSCs was $9 \%$ when used as primary therapy and $26 \%$ when used as rescue/salvage therapy [17]. The data are limited regarding the use of OTSC as a primary therapy [4]. The results of our study suggest that OTSC may be used as a primary therapy in selected cases, such as those with a high risk of rebleeding, or patients with multiple comorbidities and poor surgical risk.

There were no major adverse events associated with OTSC application in the present series. In 1 patient, asymptomatic narrowing of the duodenum (junction of first and second part) was noticed, and in another bleeding after dislodgment of the OTSC used for duodenal neuroendocrine tumor resection. Our results stand in concordance with the published literature, which reports low complication rates with the use of OTSC for various indications [9]. Adverse events reported with the application of OTSC included luminal stenosis by misplaced OTSC, micro-perforation of ulcer, maceration of perforation and abnormal suctioning of neighboring organ (ureter, small bowel while clipping colon) $[9,12]$.

Our study has several strengths. This is the first series from India to evaluate the multi-purpose utility of OTSC. The use of the novel OTSC clip for stent fixation has not been described before. The noteworthy limitations include small sample size, retrospective design and lack of a comparative arm. In addition, OTSC was used in a highly selected group of patients, which may have augmented the clinical and technical success rates.
In conclusion, OTSC is safe and effective for multiple indications in the GI tract, including GI defects, acute upper GI bleeding and fixation of esophageal stents to prevent migration. Large prospective trials are required to define the role of these clips as a primary or rescue therapy in specific indications such as GI bleeding.

\section{Summary Box}

\section{What is already known:}

- Over-the-scope clips (OTSC) are effective for various gastrointestinal (GI) disorders

- OTSC are effective for high-risk peptic ulcer bleeding lesions and can be used as primary prophylaxis rather than rescue therapy

- Clinical success for leaks and fistula closure is seen in less than two thirds of patients

\section{What the new findings are:}

- OTSC were more effective in the management of iatrogenic perforations and acute upper GI bleedings compared to fistulas

- OTSC were effective for esophageal stent fixation

- Small and acute perforations can be closed with moderate suction during OTSC application

\section{References}

1. Nabi Z. Complications of therapeutic gastroscopy/colonoscopy other than resection. Best Pract Res Clin Gastroenterol 2016;30:719-733.

2. Abougergi MS, Travis AC, Saltzman JR. The in-hospital mortality rate for upper GI hemorrhage has decreased over 2 decades in the United States: a nationwide analysis. Gastrointest Endosc 2015;81:882-888.e1.

3. Haito-Chavez Y, Law JK, Kratt T, et al. International multicenter experience with an over-the-scope clipping device for endoscopic management of GI defects (with video). Gastrointest Endosc 2014;80:610-622.

4. Manno M, Mangiafico S, Caruso A, et al. First-line endoscopic treatment with OTSC in patients with high-risk non-variceal upper gastrointestinal bleeding: preliminary experience in 40 cases. Surg Endosc 2016;30:2026-2029.

5. Wedi E, Gonzalez S, Menke D, Kruse E, Matthes K, Hochberger J. One hundred and one over-the-scope-clip applications for severe gastrointestinal bleeding, leaks and fistulas. World J Gastroenterol 2016;22:1844-1853.

6. Goenka MK, Rai VK, Goenka U, Tiwary IK. Endoscopic management of gastrointestinal leaks and bleeding with the overthe-scope clip: a prospective study. Clin Endosc 2017;50:58-63.

7. Honegger C, Valli PV, Wiegand N, Bauerfeind P, Gubler C. Establishment of over-the-scope-clips (OTSC ${ }^{\circledR}$ ) in daily endoscopic routine. United European Gastroenterol J 2017;5:247-254.

8. Law R, Prabhu A, Fujii-Lau L, Shannon C, Singh S. Stent migration following endoscopic suture fixation of esophageal self-expandable metal stents: a systematic review and meta-analysis. Surg Endosc 2018;32:675-681. 
9. Kobara $\mathrm{H}$, Mori $\mathrm{H}$, Nishiyama $\mathrm{N}$, et al. Over-the-scope clip system: A review of 1517 cases over 9 years. J Gastroenterol Hepatol 2019;34:22-30.

10. Mönkemüller K, Martínez-Alcalá A, Schmidt AR, Kratt T. The use of the over the scope clips beyond its standard use: a pictorial description. Gastrointest Endosc Clin N Am 2020;30:41-74.

11. Piyachaturawat P, Mekaroonkamol P, Rerknimitr R. Use of the over the scope clip to close perforations and fistulas. Gastrointest Endosc Clin N Am 2020;30:25-39.

12. Asokkumar R, Chin YK, Soetikno R. Complications with over the scope clip: how can we prevent it? Gastrointest Endosc Clin N Am 2020;30:75-89.

13. Kobara H, Mori H, Fujihara S, et al. Outcomes of gastrointestinal defect closure with an over-the-scope clip system in a multicenter experience: An analysis of a successful suction method. World J
Gastroenterol 2017;23:1645-1656.

14. Watanabe K, Hikichi T, Nakamura J, et al. Feasibility of esophageal stent fixation with an over-the-scope-clip for malignant esophageal strictures to prevent migration. Endosc Int Open 2017;5:E1044-E1049.

15. Mudumbi S, Velazquez-Aviña J, Neumann H, Kyanam Kabir Baig KR, Mönkemüller K. Anchoring of self-expanding metal stents using the over-the-scope clip, and a technique for subsequent removal. Endoscopy 2014;46:1106-1109.

16. Schmidt A, Gölder S, Goetz M, et al. Over-the-scope clips are more effective than standard endoscopic therapy for patients with recurrent bleeding of peptic ulcers. Gastroenterology 2018;155:674-686.

17. Chandrasekar VT, Desai M, Aziz M, et al. Efficacy and safety of over-the-scope clips for gastrointestinal bleeding: a systematic review and meta-analysis. Endoscopy 2019;51:941-949. 